\title{
Metabolic syndrome is not associated to an increased risk of low bone mineral density in men at risk for osteoporosis
}

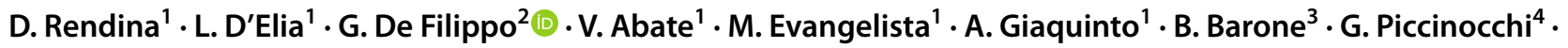 \\ D. Prezioso ${ }^{3} \cdot$ P. Strazzullo ${ }^{1}$
}

Received: 29 January 2021 / Accepted: 12 July 2021 / Published online: 27 July 2021

(c) The Author(s) 2021

\begin{abstract}
Purpose We have recently demonstrated a significant association between osteoporosis (Op) and metabolic syndrome (MetS) in Caucasian women examined by Dual-energy X-ray absorptiometry (DXA) for suspected Op. This cross-sectional study was performed to evaluate the association between MetS and Op in Caucasian men enrolled in the same geographical area, with identical criteria and in the same time range.

Methods Among subjects enrolled in the SIMON study, we selected the medical records of all free-living men who performed a contextual evaluation of both bone mineral density (BMD) by DXA and MetS constitutive elements (arterial blood pressure, waist circumference, serum levels of triglycerides, high-density lipoprotein cholesterol, and fasting glucose). All enrolled subjects refer to "COMEGEN" general practitioners' cooperative operating in Naples, Southern Italy.

Results Overall, the medical records of 880 men were examined. No significant association between MetS and Op was observed. Among MetS constitutive elements, waist circumference was inversely related to Op risk.

Conclusion In Caucasian men examined by DXA for suspected Op, no significant association was observed between Op and MetS. The study results contrast to those observed in women enrolled in the same geographical area, with identical criteria and in the same time range and may be related to sexual dimorphism occurring in clinical expressiveness of both MetS and Op.
\end{abstract}

Keywords Osteoporosis $\cdot$ Metabolic syndrome $\cdot$ Epidemiological survey $\cdot$ Waist circumference

\section{Introduction}

Metabolic syndrome (MetS) is defined by the coexistence of interconnected pathological conditions that increase the risk of type 2 diabetes mellitus (T2DM), cardiovascular diseases (CVD), and mortality for CVDs and for all-causes [1, 2]. Although several medical organizations proposed different MetS diagnostic criteria, the constitutive elements that

G. De Filippo

gianpaolo.defilippo@aphp.fr

1 Department of Clinical Medicine and Surgery, Federico II University, 80131 Naples, Italy

2 Assistance Publique-Hôpitaux de Paris, Hôpital Robert-Debré, Service d'Endocrinologie et Diabétologie, 48, Boulevard Sérurier, 75019 Paris, France

3 Department of Neuroscience Reproductive Sciences and Dentistry, Federico II University, 80131 Naples, Italy

4 “COMEGEN" Medical Cooperative, 80126 Naples, Italy are considered for MetS definition are elevation of blood pressure and glucose, abdominal obesity, and atherosclerotic dyslipidaemia in all cases $[1,2]$. Osteoporosis $(\mathrm{Op})$ is characterized by reduced bone mass, deterioration of bone tissue, and disruption of bone micro-architecture which compromise bone strength and increase the risk of fractures [3-5]. The gold standard criterion for Op diagnosis is the assessment of bone mineral density (BMD) by the dual-Xray absorptiometry (DXA) [3-5]. Both MetS and Op showed high prevalence and incidence in adult worldwide population and the World Health Organization (WHO) estimations indicate a significant and exponential increase in the incidence and prevalence of MetS and Op in both sexes in the next future caused by the aging of the worldwide populations [2-6]. Based on WHO data, in the last decades, the prevention, detection and treatment of both Op and MetS are considered a priority objective for several public health programs [7, 8]. In this regard, the Italian National Health Service (Sistema Sanitario Nazionale in Italian, $\mathrm{SSN}$ ) proposes 
(i) the BMD assessment via DXA to all women and men of any age with an Op major risk factor, and in postmenopausal women and men over the age of 60 years with at least three or more Op minor risk factors, and (ii) the global cardiovascular risk assessment by determination of all MetS constitutive elements to all women and men over the age of 39 years $[9,10]$. The SIMON (SIndrome Metabolica, Osteoporosi e Nefrolitiasi in Italian; metabolic syndrome, osteoporosis and nephrolithiasis) study is an epidemiological survey based on administrative data performed in Naples, Southern Italy, to estimate the relationship occurring between all these frequent and multifactorial disorders $[11,12]$. Thanks to the SIMON study protocol, we have recently demonstrated a significant association between Op and MetS in free-living Caucasian women referred to DXA for suspected Op [11]. Considering that all the aging-related diseases, including Op and MetS, show an evident sexual dimorphism in their clinical expressiveness [13], we used the SIMON database to perform a cross-sectional study finalised to evaluate if MetS and its constitutive elements are associated to an increased Op risk also in free-living Caucasian men with suspected Op who underwent DXA examination.

\section{Methods}

The SIMON study protocol has been extensively previously described [11, 12]. Briefly, the SIMON database is constituted by the medical records of 180,724 patients referring to the general practitioners (GPs) registered to the "COMEGEN" Medical Cooperative on June 1, 2018. For this cross-sectional study, the COMEGEN GPs selected Caucasian men who performed contemporarily the BMD assessment by DXA [International Classification of Diseases -9th revision (ICD9) code 8898] and the evaluation of the presence of MetS constitutive elements, according to the American Heart Association (AHA) /National Heart, Lung, and Blood Institute (NHLBI) Scientific Statement [14]. The COMEGEN GPs examined the time interval comprised between June 1, 2008 and May 31, 2018. On their first admission to their GPs, all patients accepted that (i) their personal data could be used for public health research purposes; (ii) they could withdraw their consent to the use of personal data without any explanation at any time and without effects on the medical assistance. This, in the form of written informed consent, was obtained from each patient or subject involved in this study. The study protocol was approved by the ASL Naples 1 Ethical Committee, protocol number 0018508/2018.

\section{Diagnostic criteria}

The Op diagnosis was made in men showing at least one of these criteria (i) a DXA T-score value $\leq-2.5$ in the lumbar spine, total hip or femoral neck [15]; (ii) personal history of clinical fragility fractures and/or anti-osteoporotic treatment independent of BMD values. Men without any diagnostic criteria were considered as controls. The MetS diagnosis was made in Caucasian men showing at least any three of the five following criteria: (1) waist circumference $\geq 102 \mathrm{~cm}$; (2) serum triglycerides $>1.7 \mathrm{mmol} / \mathrm{L}$ or current drug treatment for elevated triglycerides; (3) serum High-Density Lipoprotein cholesterol (HDL cholesterol) $<1.03 \mathrm{mmol} / \mathrm{L}$ or drug treatment for dyslipidemia; (4) systolic blood pressure (BP) $\geq 130 \mathrm{mmHg}$ and/or diastolic $\mathrm{BP} \geq 85 \mathrm{mmHg}$ or current antihypertensive drug treatment in a patient with a history of hypertension and (5) fasting serum glucose $\geq 5.6 \mathrm{mmol} / \mathrm{L}$ or drug treatment for T2DM [14]. According to Grundy and colleagues [14], to measure the waist circumference, the top of right iliac crest was located. A measuring tape was placed in a horizontal plane around abdomen at level of iliac crest. Measurement is made at the end of a normal expiration ensuring that, before reading tape measure, the tape is snug but does not compress the skin and is parallel to floor.

\section{Exclusion criteria}

The clinical records of Caucasian men with age lower than 40 years, long-term immobilization, regular use of gonadotropin-releasing hormone agonist, glucocorticoids, anticonvulsants, heparin, vitamin A, cytotoxic agents and antiandrogens, Op therapy not compliant to Italian Medicine Agency (Agenzia Italiana del FArmaco, AIFA) prescriptive criteria [16], DXA prescription not compliant to Italian Essential Assistance Levels (EAL) [9, 10], clinical conditions reported in Table 1 and incomplete data collection were excluded from this study.

\section{Statistical analysis}

All statistical analyses were performed using the IBM SPSS Statistics software, version 23 (International Business Machines Corporation, Armonk, New York) by L.D.E., who did not participate to the data extraction from "COMEGEN" Medical Cooperative database. Analysis of variance (ANOVA) or Chi-squared test was used to assess differences in the main characteristics of men who had or had not Op and/or MetS. Binary logistic regression analysis was used to estimate the influence of MetS on the risk of Op, adjusting for the main potential confounders (Model 1: age and drugs reported in Table 2; Model 2: age, drugs reported in Table 2, 
Table 1 Clinical conditions considered exclusion criteria for patients' enrolment

\begin{tabular}{ll}
\hline Clinical conditions & ICD9 codes \\
\hline Malabsorption syndromes & From 5793 to 5799 \\
Rheumatoid arthritis & 7140 \\
Moderate to severe CKD & From 5853 to 5859,586 and 6393 \\
Hyperthyroidism & From 24,200 to 24,291 \\
Primary hyperparathyroidism & From 25,200 to 25,208 \\
Hypoparathyroidism & 2521 \\
Cushing's syndrome & 2550 \\
Chronic liver disease & From 5710 to 5719 \\
Pituitary tumors & $1943,2273,2370$ \\
Surgical history of terminal ileal resection & 4562 \\
Surgical history of gastrectomy or small bowel bypass & From 430 to 4499 \\
Eating disorders & 3071, from 30,750 to 30,759 \\
Alcoholism & From 30,390 to 30,393 \\
\hline
\end{tabular}

ICD9 International Classification of Diseases 9th revision, $C K D$ chronic kidney disease
Table 2 Use of drugs associated to reduced BMD in SIMON study cohorts

\begin{tabular}{llll}
\hline Drugs & Op $(n=552)$ & Controls $(n=328)$ & $p$ \\
\hline $\begin{array}{l}\text { Proton pump inhibitors } \\
(n ; \%)\end{array}$ & $338 ; 61.2$ & $190 ; 57.9$ & 0.36 \\
$\begin{array}{l}\text { Thiazolidinediones }(n ; \%) \\
\text { Antiretroviral therapy }(n ;\end{array}$ & $20 ; 3.6$ & $16 ; 4.9$ & 0.38 \\
$\quad \%)$ & & $30 ; 9.1$ & 0.81 \\
Loop diuretics $(n ; \%)$ & $92 ; 16.7$ & $50 ; 15.2$ & 0.64 \\
$\begin{array}{l}\text { Calcineurin inhibitors }(n ; \\
\%)\end{array}$ & $4 ; 0.7$ & $2 ; 0.6$ & 0.98 \\
\hline
\end{tabular}

Data are expressed as absolute; percentage number

$p$ values were determined using Chi-squared test

$B M D$ bone mineral density. SIMON sindrome metabolica, osteoporosi e nefrolitiasi in Italian; metabolic syndrome, osteoporosis and nephrolithiasis. $O p$ SIMON men with clinical diagnosis of osteoporosis. Controls SIMON men without clinical diagnosis of osteoporosis

and numbers of MetS constitutive elements; Model 3: age, drugs reported in Table 2, and the individual MetS constitutive elements). The results are reported as mean and standard deviation (SD) as percentages or as odds ratio (OR) and 95\% confidence intervals $(95 \% \mathrm{CI})$, unless otherwise indicated. All reported $\mathrm{p}$ values are two-sided, and the significant level was set at $p<0.05$.

\section{Results}

According to exclusion and inclusion criteria previously exposed, the medical records of 880 Caucasian men [mean age $73.5 \pm 9.0$ years; range $42-90$ years Body Mass Index (BMI) $\left.26.9 \pm 4.1 \mathrm{~kg} / \mathrm{m}^{2}\right]$ were selected and examined. Five hundred fifty two have Op clinical diagnosis (Op patients; mean age $73.9 \pm 9.0$ years; BMI $26.6 \pm 4.1 \mathrm{~kg} / \mathrm{m}^{2}$ ), whereas the remaining 328 men without Op diagnosis were considered as controls (mean age $72.7 \pm 8.8$ years; BMI $\left.27.6 \pm 4.0 \mathrm{~kg} / \mathrm{m}^{2}\right)$. Op patients showed a significantly lower BMI compared to controls $(p<0.01)$.

Overall, 827 men had hypertension or current antihypertensive treatment (mean age $73.9 \pm 8.7$ years; BMI $27.0 \pm 4.1 \mathrm{~kg} / \mathrm{m}^{2} ; 518$ with Op), 609 subjects had high fasting serum glucose or T2DM (mean age $73.3 \pm 8.9$ years; BMI $27.4 \pm 4.3 \mathrm{~kg} / \mathrm{m}^{2}$; 375 with Op), 716 men had low serum HDL cholesterol or current drug treatment (mean age $73.5 \pm 8.7$ years; BMI $27.1 \pm 4.0 \mathrm{~kg} / \mathrm{m}^{2} ; 450$ with $\mathrm{Op}$ ), 707 men had high serum triglycerides or current drug treatment (mean age $73.3 \pm 8.6$ years; BMI $27.1 \pm 4.1 \mathrm{~kg} / \mathrm{m}^{2}$; 443 with Op), 436 men had high waist circumference (mean age $73.7 \pm 9.2$ years; BMI $30.1 \pm 3.1 \mathrm{~kg} / \mathrm{m}^{2} ; 248$ with Op). Twenty men (mean age $65.1 \pm 11.0$ years; BMI $23.8 \pm 1.5 \mathrm{~kg} /$ $\mathrm{m}^{2} ; 17$ with Op) did not have any MetS constitutive element, 40 men (mean age $74.0 \pm 10.3$ years; $23.6 \pm 2.2 \mathrm{~kg} / \mathrm{m}^{2} ; 24$ with Op) had a single MetS constitutive element, while 76 men (mean age $75.9 \pm 9.3$ years; BMI $26.0 \pm 3.7 \mathrm{~kg} / \mathrm{m}^{2} ; 43$ with Op) had two MetS constitutive elements. The remaining 744 men have MetS showing at least three MetS constitutive elements (mean age $73.4 \pm 73.8$ years; BMI $27.3 \pm 4.1 \mathrm{~kg} /$ $\left.\mathrm{m}^{2}\right)$ : of these, $468(63 \%$; mean age $74.0 \pm 8.7$ years; BMI $26.9 \pm 4.1 \mathrm{~kg} / \mathrm{m}^{2}$ ) had Op diagnosis.

In the study population, Op and MetS were not significantly associated (OR 1.04; 95\% CI $0.71-1.51 ; p=0.80$ ) and the Op prevalence did not increase, increasing the numbers of MetS constitutive elements ( $p$ for trend $=0.06$ ). In a separate logistic regression model including the individual components of MetS (Table 3), waist circumference was the only MetS constitutive elements related to the occurrence of Op, accounting for age, all the other MetS constitutive elements, and ongoing treatments. 
Table 3 Risk of osteoporosis and metabolic syndrome constitutive elements in study cohort

\begin{tabular}{lllr}
\hline $\begin{array}{l}\text { MetS constitutive } \\
\text { elements }\end{array}$ & Odds ratio & $\begin{array}{l}\text { 95\% confi- } \\
\text { dence interval }\end{array}$ & $p$ \\
\hline Hyperglycaemia/T2DM & 0.90 & $0.66-1.24$ & 0.50 \\
Hypertension & 0.91 & $0.48-1.68$ & 0.78 \\
Low HDL cholesterol levels & 1.14 & $0.60-2.14$ & 0.72 \\
Hypertriglyceridaemia & 0.99 & $0.54-1.91$ & 0.99 \\
High waist circumference & 0.60 & $0.47-0.80$ & $<0.01$ \\
\hline
\end{tabular}

Hyperglycaemia/T2DM: fasting serum glucose $\geq 5.6 \mathrm{mmol} / \mathrm{L}$ or drug treatment for T2DM; Hypertension: systolic blood pressure (BP) $\geq 130 \mathrm{mmHg}$ and/or diastolic $\mathrm{BP} \geq 85 \mathrm{mmHg}$ or current antihypertensive drug treatment in a patient with a history of hypertension; Low HDL cholesterol levels: serum HDL cholesterol $<1.03 \mathrm{mmol} /$ Lor drug treatment for dyslipidemia. Hypertriglyceridemia: serum triglycerides $>1.7 \mathrm{mmol} / \mathrm{L}$ or current drug treatment for elevated triglycerides; High waist circumference: waist circumference $\geq 102 \mathrm{~cm}$; The MetS diagnosis was made in men who fulfilled any three of the previously exposed criteria [14]

MetS metabolic syndrome; T2DM: type 2 diabetes mellitus; $H D L$ high-density lipoprotein

\section{Discussion}

The study results do not demonstrate a significant association between MetS and Op in free-living Caucasian men from Southern Italy undergoing to DXA for suspected Op. This study is part of the SIMON study protocol [11, 12]. Within the SIMON protocol, we have recently performed a study aimed to evaluate the relationship between MetS and Op in free-living women at risk of osteoporosis, according to the Italian EAL [11]. Both men and women enrolled in the SIMON study live in the same geographic area and were enrolled in the same time laps $[11,12]$. Unlike what was observed in SIMON men, a significant association between MetS and Op was observed among SIMON women [11]. However, the SIMON women cohort is larger $(13,182$ participants) and younger (mean age $62.8 \pm 9.4$ years) compared to SIMON men cohort. These differences prompted a separate analysis of the two cohorts and may justify the different clinical characteristics of men and women enrolled in the SIMON study [11]. In effect, the prevalence of MetS ( $84.5 \%$ vs. $59.3 \%$ for men and women, respectively) and Op (62.7\% vs. $84.4 \%$ for men and women, respectively) is different in SIMON men and SIMON women [11]. Also, the prevalence of high blood pressure/hypertension $(94.0 \%$ vs. $84.1 \%$ for men and women, respectively), high serum triglycerides ( $80.3 \%$ vs. $56.5 \%$ for men and women, respectively), high fasting serum glucose and/or T2DM (69.2\% vs. $28.1 \%$ for men and women, respectively), low HDL cholesterol ( $81.4 \%$ vs. $54.4 \%$ for men and women, respectively) and high waist circumference $(49.5 \%$ vs. $66.3 \%$ for men and women, respectively) is significantly different in
SIMON men and SIMON women [11]. MetS and Op are two major public health problems with enormous human, social, and financial cost. Both disorders showed a similar and complex pathogenesis characterized by the interaction between non-modifiable and modifiable risk factors, such as unhealthy dietary habits and low physical activity $[7,8]$. Even disorders of vitamin $\mathrm{D}$ and calciotropic hormones may be implicated in the pathogenesis of both disorders [17, 18]. Epidemiological surveys however demonstrated that both MetS and Op are characterized by a sexual dimorphism in their clinical expressiveness [13]. In effect, the Op prevalence is significantly higher in women than in men; in 2010, there were 22 million women and 5.5 million men affected by Op in Europe [19, 20]. From a clinical point of view, men show a lower lifetime fracture risk compared to women (13-25\% vs 50\%) [21]. In absolute numbers, the prevalence of vertebral or hip fracture in elderly men is approximately one-third of that in women, but on the contrary, the mortality rate associated with hip fractures, as well as vertebral and other major fractures, is higher in men than in women [22-25]. Regarding MetS, a large population-based project enrolling 36 cohorts from 10 European countries (the MOnica, Risk, Genetics, Archiving and Monograph-MORGAM project) [26] found that the prevalence of MetS was more than doubled in women when compared to men in a population aged 19-39 to 60-78 years old. When individually analysing the patterns of MetS components, men showed a higher prevalence of arterial hypertension and hypertriglyceridemia, while women had more frequently increased waist circumference and low HDL cholesterol levels. According to these results, Dallongeville and colleagues demonstrated that elevated waist circumference and low HDL cholesterol were significantly larger contributors to MetS in women than in men, while hypertension was the metabolic disorder most frequently found in men than in women [27]. These phenomena may be linked to different physiological role of mitochondrial malfunction and abnormal mitochondrial-nuclear signalling and of sexual hormones in the two genders through the lifespan from birth to senescence [13, 28-30]. Analysing the influence of each MetS constitutive element on Op diagnosis, the study results indicate that higher waist circumference is associated to a reduced risk of low BMD in men at increased risk of osteoporosis according to the Italian EAL. This association was independent of others MetS constitutive elements. Different studies analysed the associations between some adiposity indices, including waist circumference, and BMD or osteoporosis [31-35]. These studies were preferentially performed in women and furnish contradictory findings, probably for the different inclusion criteria of covariates used in the statistical models used for evaluate the possible association. The mechanisms proposed to explain the inverse association between obesity and BMD are essentially two. The obese subjects may have 
higher BMD for the elevated mechanical load of lean and fat mass on the bones and/or for the anabolic stimulus provided on bone formation by some adipocytokines, in particular adiponectin and resistin [36-39].

\section{Strength and limits}

The SIMON study is based on an administrative database, a study methodology showing well-defined strengths and limits [40]. Certainly, the Op diagnosis based upon administrative health database has an acceptable level of sensitivity, specificity, and accuracy, especially when the assumption of anti-osteoporotic drugs was used as additional information in the query formulation, as in our study [41]. Also, MetS diagnostic criteria used in SIMON protocol are suitable for epidemiological studies [2] and have been previously used in studies with similar characteristics [11, 42, 43]. In this regard, it should be noted that in 2009, some important health organizations, including AHA and NHLBI, met to draft a Joint Scientific Statement (JSS) with the intention of harmonizing the MetS diagnosis worldwide [44]. Not surprisingly, a large part of the JSS is devoted to discussing the diagnosis of abdominal obesity. As admitted in the JSS, the definition of the cut-off points for abdominal obesity is complicated by several factors, including ethnic origin. For Caucasian subjects, a waist circumference $\geq 102 \mathrm{~cm}$ in men correspond to a BMI $\geq 30 \mathrm{~kg} / \mathrm{m}^{2}$ [45]. Finally, we enrolled a large and homogeneous population. On the other hand, the limits related to use of administrative data should be declared. We are unable (a) to evaluate if the anatomical site of DXA exam furnishing pathological BMD finding (i.e. lumbar, femoral or ulnar site) influences the study results, (b) to estimate the role of metabolic and dietary risk factors for both Op and MetS in the observed results, and (c) to improve the quality of available data evaluating the trabecular bone score and the occurrence of vertebral fractures using vertebral morphometry. A crucial point is the generalizability of study results. In effect, the study cohort is representative for all free-living adult men (i.e. over 40 years old), without pathology associated with secondary Op, undergoing DXA evaluation of BMD basing on Italian EAL and not for the entire Italian adult male free-living population. The selection criteria also account for the high prevalence of Op and MetS constitutive elements observed in the study cohort.

In conclusion, the present study demonstrates that MetS is not associated to an increased Op risk in Caucasian men in whom skeletal health was evaluated by DXA exam according to Italian EAL. The comparison of the results of the present study to those obtained in women enrolled in the same geographical region and in the same lapse of time suggests the occurrence of a sexual dimorphism in the clinical expressiveness of MetS and Op. Further ad hoc studies are necessary to confirm this intriguing hypothesis.
Author contributions All authors contributed to the study conception and design. Material preparation and data collection were performed by DR, GP, GDF, AG, VA, BB and ME. The statistical analysis was performed by LDE who did not participate in data collection. The first draft of the manuscript was written by DR and GDF. All authors commented on previous versions of the manuscript. All authors read and approved the final manuscript.

Funding Open access funding provided by Università degli Studi di Napoli Federico II within the CRUI-CARE Agreement. This is an unfunded study.

Data availability The datasets generated during and/or analysed during the current study are available from the corresponding author on reasonable request.

\section{Declarations}

Conflict of interest The authors declare that they have no conflict of interest.

Ethical approval This retrospective study involving human participants was performed in accordance with the ethical standards of the institutional and national research committee and with the 1964 Helsinki Declaration and its later amendments or comparable ethical standards. The study protocol was approved by the ASL Naples 1 Ethical Committee, protocol number 0018508/2018.

Informed consent Informed consent was obtained from all individual participants included in the study.

Open Access This article is licensed under a Creative Commons Attribution 4.0 International License, which permits use, sharing, adaptation, distribution and reproduction in any medium or format, as long as you give appropriate credit to the original author(s) and the source, provide a link to the Creative Commons licence, and indicate if changes were made. The images or other third party material in this article are included in the article's Creative Commons licence, unless indicated otherwise in a credit line to the material. If material is not included in the article's Creative Commons licence and your intended use is not permitted by statutory regulation or exceeds the permitted use, you will need to obtain permission directly from the copyright holder. To view a copy of this licence, visit http://creativecommons.org/licenses/by/4.0/.

\section{References}

1. Stern MP, Williams K, González-Villalpando C, Hunt KJ, Haffner SM (2004) Does the metabolic syndrome improve identification of individuals at risk of type 2 diabetes and/or cardiovascular disease? Diabetes Care 27:2676-2681

2. Grundy SM (2016) Metabolic syndrome update. Trends Cardiovasc Med 26:364-373

3. Word Health Organization (2020) WHO Scientific Group on the assessment of osteoporosis at primary health care level. https:// who.int/chp/topics/Osteoporosis.pdf. Accessed 27 Feb 2021

4. International Osteoporosis Foundation (2019) Facts and statistics. https://www.iofbonehealth.org/facts-statistics. Accessed $27 \mathrm{Feb}$ 2021

5. Italian Major Health Institute (2019) Focus on osteoporosis http:// www.epicentro.iss.it/focus/osteoporosi/osteoporosi. Accessed 27 Feb 2021 
6. Golden SH, Robinson KA, Saldanha I, Anton B, Ladenson PW (2009) Clinical review: prevalence and incidence of endocrine and metabolic disorders in the United States: a comprehensive review. J Clin Endocrinol Metab 94:1853-1878

7. Zimmet P, Magliano D, Matsuzawa Y, Alberti G, Shaw J (2005) The metabolic syndrome: a global public health problem and a new definition. J Atheroscler Thromb 12:295-300

8. Harvey N, Dennison E, Cooper C (2010) Osteoporosis: impact on health and economics. Nat Rev Rheumatol 6:99-105

9. Nuti R, Brandi ML, Checchia G, Di Munno O, Dominguez L, Falaschi P, Fiore CE, Iolascon G, Maggi S, Michieli R, Migliaccio S, Minisola S, Rossini M, Sessa G, Tarantino U, Toselli A, Isaia GC (2019) Guidelines for the management of osteoporosis and fragility fractures. Intern Emerg Med 14:85-102

10. Italian Ministry of Health (2005) Essential assistance levels for DXA. http://www.salute.gov.it/imgs/C_17_pubblicazioni_1171_ allegato.pdf. Accessed on 14 June 2020

11. Rendina D, D'Elia L, Evangelista M, De Filippo G, Giaquinto A, Abate V, Barone B, Piccinocchi G, Prezioso D, Strazzullo P (2021) Metabolic syndrome is associated to an increased risk of low bone mineral density in free-living women with suspected osteoporosis. J Endocrinol Invest 44:1321-1326

12. Rendina D, D'Elia L, Evangelista M, De Filippo G, Giaquinto A, Barone B, Piccinocchi G, Prezioso D, Strazzullo P (2020) Osteoporosis is a predictive factor for nephrolithiasis in an adult freeliving Caucasian population from Southern Italy: a longitudinal retrospective study based on a general practice database. Calcif Tissue Int 107(5):446-452

13. Tower J (2017) Sex-specific gene expression and life span regulation. Trends Endocrinol Metab 28:735-747

14. Grundy SM, Cleeman JI, Daniels SR, Donato KA, Eckel RH, Franklin BA, Gordon DJ, Krauss RM, Savage PJ, Smith SC Jr, Spertus JA, Costa F, American Heart Association, National Heart Lung and Blood Institute (2005) Diagnosis and management of the metabolic syndrome: an American Heart Association/National Heart, Lung, and Blood Institute Scientific Statement. Circulation 112:2735-2752

15. Kanis JA, Melton LJ 3rd, Christiansen C, Johnston CC, Khaltaev N (1994) The diagnosis of osteoporosis. J Bone Miner Res 9:1137-1141

16. Italian Medicines Agency (AIFA) Note 79 of Italian Medicines Agency for the appropriate use of the drugs http://www.agenziafar maco.gov.it/content/nota-79. Accessed 27 Feb 2021

17. Dusso AS, Brown AJ, Slatopolsky E (2005) Vitamin D. Am J Physiol Renal Physiol 289:F8-28

18. Rendina D, De Filippo G, Muscariello R, De Palma D, Fiengo A, De Pascale F, Strazzullo P (2014) Vitamin D and cardiometabolic disorders. High Blood Press Cardiovasc Prev 21:251-256

19. Svedbom A, Hernlund E, Ivergård $M$, Compston J, Cooper C, Stenmark J, McCloskey EV, Jönsson B, Kanis JA, EU Review Panel of IOF (2013) Osteoporosis in the European Union: a compendium of country-specific reports. Arch Osteoporos 8:137

20. Hernlund $\mathrm{E}$, Svedbom A, Ivergård $\mathrm{M}$, Compston J, Cooper C, Stenmark J, McCloskey EV, Jonsson B, Kanis JA (2013) Osteoporosis in the European Union: medical management, epidemiology and economic burden: a report prepared in collaboration with the International Osteoporosis Foundation (IOF) and the European Federation of Pharmaceutical Industry Associations (EFPIA). Arch Osteoporos 8:136

21. Gennari L, Bilezikian JP (2013) Idiopathic osteoporosis in men. Curr Osteoporos Rep 11:286-298

22. Center JR, Nguyen TV, Schneider D, Sambrook PN, Eisman JA (1999) Mortality after all major types of osteoporotic fracture in men and women: an observational study. Lancet 353:878-882

23. Haentjens P, Magaziner J, Colón-Emric CS, Vandershueren D, Millisen K, Velkeniers B, Boonen S (2010) Meta-analysis: excess mortality after hip fracture among older women and men. Ann Intern Med 152:380-390

24. Cummings SR, Melton LJ (2002) Epidemiology and outcomes of osteoporotic fractures. Lancet 359:1761-1767

25. Bliuc D, Alarkawi D, Nguyen TV, Eisman JA, Center JR (2015) Risk of subsequent fractures and mortality in elderly women and men with fragility fractures with and without osteoporotic bone density: the dubbo osteoporosis epidemiology Study. J Bone Min Res 30:637-646

26. Vishram JK, Borglykke A, Andreasen AH, Jeppesen J, Ibsen H, Jørgensen T, Palmieri L, Giampaoli S, Donfrancesco C, Kee F, Mancia G, Cesana G, Kuulasmaa K, Salomaa V, Sans S, Ferrieres J, Dallongeville J, Söderberg S, Arveiler D, Wagner A, Tunstall-Pedoe H, Drygas W, Olsen MH, MORGAM Project (2014) Impact of age and gender on the prevalence and prognostic importance of the metabolic syndrome and its components in Europeans. The MORGAM Prospective Cohort Project. PLoS ONE 9:e107294

27. Dallongeville J, Cottel D, Arveiler D, Tauber JP, Bingham A, Wagner A, Fauvel J, Ferrières J, Ducimetière P, Amouyel P (2004) The association of metabolic disorders with the metabolic syndrome is different in men and women. Ann Nutr Metab 48:43-50

28. Faulkner JL, Belin de Chantemèle EJ (2019) Sex hormones, aging and cardiometabolic syndrome. Biol Sex Differ 10:30

29. Almeida M, Laurent MR, Dubois V, Claessens F, O'Brien CA, Bouillon R, Vanderschueren D, Manolagas SC (2017) Estrogens and androgens in skeletal physiology and pathophysiology. Physiol Rev 97:135-187

30. Farr JN, Khosla S (2015) Skeletal changes through the lifespanfrom growth to senescence. Nat Rev Endocrinol 11:513-521

31. Morin S, Leslie WD, Manitoba Bone Density Program (2009) High bone mineral density is associated with high body mass index. Osteoporos Int 20:1267-1271

32. Tomlinson DJ, Erskine RM, Morse CI, Onambélé G (2019) Body fat percentage, body mass index, fat mass index and the ageing bone: their singular and combined roles linked to physical activity and diet. Nutrients 11:195

33. Kim HY, Choe JW, Kim HK, Bae SJ, Kim BJ, Lee SH, Koh JM, Han KO, Park HM, Kim GS (2010) Negative association between metabolic syndrome and bone mineral density in Koreans, especially in men. Calcif Tissue Int 86:350-358

34. Liu X, Wu W, Mao Z, Huo W, Tu R, Qian X, Zhang X, Tian Z, Zhang H, Jiang J, Li Y, Wang C (2018) Prevalence and influencing factors of overweight and obesity in a Chinese rural population: the henan rural cohort study. Sci Rep 30(8):13101

35. Tian H, Pan J, Qiao D, Dong X, Li R, Wang Y, Tu R, Abdulai T, Liu X, Hou J, Zhang G, Wang C (2020) Adiposity reduces the risk of osteoporosis in Chinese rural population: the Henan rural cohort study. BMC Public Health 4(20):285

36. Zhao LJ, Jiang H, Papasian CJ, Maulik D, Drees B, Hamilton J, Deng HW (2008) Correlation of obesity and osteoporosis: effect of fat mass on the determination of osteoporosis. J Bone Miner Res 23:17-29

37. Bierhals IO, Dos Santos VJ, Bielemann RM, de Mola CL, Barros FC, Gonçalves H, Wehrmeister FC, Assunção MCF (2019) Associations between body mass index, body composition and bone density in young adults: findings from a southern Brazilian cohort. BMC Musculoskelet Disord 20:322

38. Wang Y, Zhang X, Shao J, Liu H, Liu X, Luo E (2017) Adiponectin regulates BMSC osteogenic differentiation and osteogenesis through the Wnt/ $\beta$-catenin pathway. Sci Rep 7:3652

39. Thommesen L, Stunes AK, Monjo M, Grøsvik K, Tamburstuen MV, Kjøbli E, Lyngstadaas SP, Reseland JE, Syversen U (2006) Expression and regulation of resistin in osteoblasts and osteoclasts indicate a role in bone metabolism. J Cell Biochem 99:824-834 
40. Johnson EK, Nelson CP (2013) Values and pitfalls of the use of administrative databases for outcomes assessment. J Urol 190:17-18

41. Leslie WD, Lix LM, Yogendran MS (2011) Validation of a case definition for osteoporosis disease surveillance. Osteoporos Int 22:37-46

42. Rendina D, De Filippo G, Mossetti G, Zampa G, Muscariello R, Benvenuto G, Vivona CL, Ippolito S, Galante F, Lombardi G, Biondi B, Strazzullo P (2012) Relationship between metabolic syndrome and multinodular non-toxic goiter in an inpatient population from a geographic area with moderate iodine deficiency. $\mathbf{J}$ Endocrinol Invest 35:407-412

43. Rendina D, Mossetti G, De Filippo G, Benvenuto D, Vivona CL, Imbroinise A, Zampa G, Ricchio S, Strazzullo P (2009) Association between metabolic syndrome and nephrolithiasis in an inpatient population in southern Italy: role of gender, hypertension and abdominal obesity. Nephrol Dial Transplant 24:900-906

44. Alberti KG, Eckel RH, Grundy SM, Zimmet PZ, Cleeman JI, Donato KA, Fruchart JC, James WP, Loria CM, Smith SC Jr,
International Diabetes Federation Task Force on Epidemiology and Prevention; Hational Heart, Lung, and Blood Institute; American Heart Association; World Heart Federation; International Atherosclerosis Society; International Association for the Study of Obesity (2009) Harmonizing the metabolic syndrome: a joint interim statement of the International Diabetes Federation Task Force on Epidemiology and Prevention; National Heart, Lung, and Blood Institute; American Heart Association; World Heart Federation; International Atherosclerosis Society; and International Association for the Study of Obesity. Circulation 120:1640-1645

45. Silva V, Stanton KR, Grande AJ (2013) Harmonizing the diagnosis of metabolic syndrome-focusing on abdominal obesity. Metab Syndr Relat Disord 11:102-108

Publisher's Note Springer Nature remains neutral with regard to jurisdictional claims in published maps and institutional affiliations. 